\title{
A Public Health Perspective on Influenza Status in the Context of COVID-19 Pandemic, 2019-2020
}

\author{
Xiang Huo'; Fengcai Zhu ${ }^{1, * t}$
}

The possible dual epidemic of coronavirus disease 2019 (COVID-19) and influenza in the coming winter raises serious concerns for the northern hemisphere as it will likely result in an expanded disease burden and overloading of public health institutions and clinical capacities as a result of continued increasing mental stress for the public and depletion of public resources. Several questions remain regarding how the flu season might affect the COVID-19 pandemic and vice versa.

\section{DECREASED INFLUENZA ACTIVITY AND POTENTIAL CONTRIBUTORS}

Some signs of the interaction between the flu and COVID-19 were shown in the past flu season in the southern hemisphere. Australia, Chile, and South Africa recorded not only much lower influenza activity compared with usual seasons, but fewer positive test results of influenza viruses - 51 influenza positive specimens out of 83,307 samples, or $0.06 \%$ [95\% confidence interval (95\% CI): 0.04-0.08] (1). In the northern hemisphere, the United States, Republic of Korea, and Singapore reported an interruption to the then ongoing influenza circulation of the 2019-2020 season and a historically low interseasonal level of influenza incidence (1-3). Reduced activity was also observed for other common respiratory viral agents (4).

Non-pharmaceutical interventions (NPI) aimed against COVID-19 were supposed to be responsible for reducing transmission of influenza. A range of mitigation measures focusing on social distancing, including bans on mass gatherings, school closures, teleworking, and national or regional lockdowns, have been widely implemented for COVID-19 and whose effectiveness has been demonstrated by the corresponding incidence curves of many countries across the world, such as China, Germany, Australia, and South Africa (5). These community measures, in addition to recommended or mandatory individual measures against COVID-19 such as mask wearing and hand hygiene, can also curb the transmission of the seasonal influenza virus that shares same transmission routes with COVID-19 (G) but is less contagious $\left(R_{0}=1.28\right.$ for the flu compared to $R_{0}=2-3.5$ for COVID-19) (7). Among these mitigation measures, school closures may have played an additional role in reducing transmission in children, who are important drivers of influenza virus transmission in the community (G).

Viral interference could also be at play (8-9) as infection with a virus can prevent or partially inhibit infection with another virus within the same host (9). The interference is variable between virus-pairs and could be modified by the time interval from primary to secondary viral exposure $(8,10)$. In COVID-19 patients, the infection rate with non-COVID-19 respiratory viral pathogens was much lower than that in non-COVID-19 patients during the same time period $(2.99 \%$ vs. $13.1 \%)$, which suggested a competitive advantage of COVID-19 in the interaction with other respiratory viruses including influenza (11).

\section{COINFECTION AND PRIOR INFECTION WITH INFLUENZA}

The coinfection rate of COVID-19 with other respiratory viral pathogens was reported vary widely between $0 \%$ to $25 \%$, with a pooled estimate of $3 \%$ (12). The variety of virus targeted, the detection method used, and the seasonality of other respiratory viral pathogens during the research period (13) may contribute to heterogeneity among studies. Among the identified coinfected viral pathogens, influenza virus was among the most common (12).

Coinfection with influenza virus has been reported in Middle East respiratory syndrome (MERS) cases (14). The coinfection rate with influenza virus was generally low in confirmed COVID-19 patients with a combination of different clinical severities $(0.1 \%$ 2.7\%), according to studies using PCR-based testing methods across the world, from Switzerland (4), Brazil 
(15), the United States (16-17), Spain (18), and China (19-20). Although the clinical impact of coinfection has not been conclusive, some evidence has suggested that coinfection with influenza virus may worsen the clinical outcome of COVID-19 patients. In coinfected patients, substantially higher neutrophils and inflammatory markers and higher incidence of acute cardiac injury were observed (21), and the risk of ventilator use and death was elevated (22), in which the provoked hyperinflammatory state and the upregulated pulmonary angiotensin-converting enzyme 2 (ACE2) receptors induced by influenza virus infection might play a role (23-24). In a study conducted in Iran, $22.3 \%$ of the dead COVID-19 patients were coinfected with influenza virus (25).

In contrast, the rate of recent influenza infection was high in COVID-19 patients (26). Over a half of the confirmed COVID-19 patients in a hospital in Wuhan, China tested positive for the influenza immunoglobulin M (IgM) antibody test (26). A study in Italy observed that $63.6 \%$ of COVID-19 patients reported a recent (1-3 weeks) influenza-like-illness prior to the appearance of COVID-19-related symptoms (27). Thus, the upper airway mucosal damage and local immune impairment triggered by prior infection may predispose individuals for subsequent COVID-19 infection (27).

\section{THE ROLE OF INFLUENZA VACCINATION}

To reduce the public health, economic, and societal hardship associated with long-term stringent lockdown measures, many countries have been relieving public health and social measures against COVID-19, but a resurgence of COVID-19 cases has been observed to follow in many countries and areas (28). The transmission activity of other respiratory viruses, particularly influenza, could also spike along with the relief of NPI against COVID-19 in the coming winter of the northern hemisphere, challenging the already stressed public health and healthcare capacities. This spike may be more obvious in countries or territories where society has returned to a certain level of normalcy.

To reduce the epidemiological noise of influenza in the context of COVID-19, mass influenza vaccinations are strongly recommended. However, this would be tricky given the tampered routine immunization services as manufacturing capacity is diverted to
COVID-19 and other vaccines. In that case, the elderly, healthcare workers, etc., could be targeted as priority groups for influenza vaccination due to risks of elevated mortality and exposure and the importance of maintaining healthcare services.

In addition to the potential of avoiding complicated coinfections, the influenza vaccination was found to be associated with lower risk of infection, severe clinical manifestation, and death with COVID-19 at the individual level (29-31). At the population level, an ecological study also showed that the coverage rate of the influenza vaccination in people aged 65 or over was associated with a reduced spread and a less severe clinical presentation of COVID-19 (32). It is possible that influenza vaccination could act as a non-specific immune stimulator leading to earlier activation of the immune system to combat COVID-19 (33).

Nevertheless, the effectiveness of influenza vaccine is generally modest and even lower in individuals aged 65 years or older, who are at higher risk of severe infection for both the influenza virus and COVID-19. Mismatch between the circulating influenza strains and the vaccine influenza strains would further jeopardize the vaccine's effectiveness. This is more likely to happen in the next influenza season of southern hemisphere, as very few isolates of influenza virus were able to be collected in the past flu season making it especially difficult to predict the upcoming circulating strains. Thus, faster and more widely available testing is needed to distinguish between the influenza virus and COVID-19, which cause similar symptoms but requires different treatments and emergency response strategies. In addition, some NPI including wearing mask and social distance should be preserved as the new standard until a valid COVID-19 vaccine is available.

doi: $10.46234 / \mathrm{ccdcw} 2020.231$

\# Corresponding author: Fengcai Zhu, jszfc@vip.sina.com.

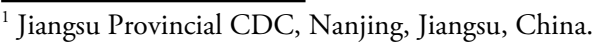

Submitted: October 19, 2020; Accepted: October 27, 2020

\section{REFERENCES}

1. Olsen SJ, Azziz-Baumgartner E, Budd AP, Brammer L, Sullivan S, Pineda RF, et al. Decreased influenza activity during the COVID-19 pandemic - United States, Australia, Chile, and South Africa, 2020. MMWR Morb Mortal Wkly Rep 2020;69(37):1305-9. http://dx.doi.org/10.15585/mmwr.mm6937a6.

2. Lee H, Lee H, Song KH, Kim ES, Park JS, Jung J, et al. Impact of public health interventions on seasonal influenza activity during the COVID-19 outbreak in Korea. Clin Infect Dis 2020. http://dx.doi.org/ 
$10.1093 / \mathrm{cid} / \mathrm{ciaa} 672$.

3. Soo RJJ, Chiew CJ, Ma S, Pung R, Lee V. Decreased influenza incidence under COVID-19 control measures, Singapore. Emerg Infect Dis 2020;26(8):1933 - 5. http://dx.doi.org/10.3201/eid2608.201229.

4. Leuzinger K, Roloff T, Gosert R, Sogaard K, Naegele K, Rentsch K, et al. Epidemiology of severe acute respiratory syndrome coronavirus 2 emergence amidst community-acquired respiratory viruses. J Infect Dis 2020;222(8):1270 - 9. http://dx.doi.org/10.1093/infdis/jiaa464.

5. Roser M, Ritchie H, Ortiz-Ospina E, Hasell J. Coronavirus pandemic (COVID-19). Our world in Data. 2020. https://ourworldindata. org/coronavirus. [2020-8-30].

6. Q\&A Influenza and COVID-19 - similarities and differences. https:// www.who.int/westernpacific/news/q-a-detail/q-a-similarities-anddifferences-covid-19-and-influenza. [2020-9-29].

7. Biggerstaff M, Cauchemez S, Reed C, Gambhir M, Finelli L. Estimates of the reproduction number for seasonal, pandemic, and zoonotic influenza: a systematic review of the literature. BMC Infect Dis 2014; 14:480. http://dx.doi.org/10.1186/1471-2334-14-480.

8. Laurie KL, Guarnaccia TA, Carolan LA, Yan AWC, Aban M, Petrie S, et al. Interval between infections and viral hierarchy are determinants of viral interference following influenza virus infection in a ferret model. J Infect Dis 2015;212(11):1701 - 10. http://dx.doi.org/10.1093/infdis/ jiv260.

9. Schultz-Cherry S. Viral interference: the case of influenza viruses. J Infect Dis 2015;212(11):1690 - 1. http://dx.doi.org/10.1093/infdis/ jiv261

10. Greer RM, McErlean P, Arden KE, Faux CE, Nitsche A, Lambert SB, et al. Do rhinoviruses reduce the probability of viral co-detection during acute respiratory tract infections? J Clin Virol 2009;45(1):10 - 5. http://dx.doi.org/10.1016/j.jcv.2009.03.008.

11. Nowak MD, Sordillo EM, Gitman MR, Paniz Mondolfi AE Coinfection in SARS-CoV-2 infected patients: where are influenza virus and rhinovirus/enterovirus? J Med Virol 2020;92(10):1699 - 700 http://dx.doi.org/10.1002/jmv.25953.

12. Lansbury L, Lim B, Baskaran V, Lim WS. Co-infections in people with COVID-19: a systematic review and meta-analysis. J Infect 2020;81 (2):266 - 75. http://dx.doi.org/10.1016/j.jinf.2020.05.046.

13. Huo X, Qin YF, Qi X, Zu RQ, Tang FY, Li L, et al. Surveillance of 16 respiratory viruses in patients with influenza - like illness in Nanjing, China. J Med Virol 2012;84(12):1980 - 4. http://dx.doi.org/10.1002/ jmv.23401.

14. Alfaraj SH, Al-Tawfiq JA, Alzahrani NA, Altwaijri TA, Memish ZA. The impact of co-infection of influenza A virus on the severity of Middle East respiratory syndrome coronavirus. J Infect 2017;74 (5):521 - 3. http://dx.doi.org/10.1016/j.jinf.2017.02.001

15. de Souza WM, Buss LF, da Silva Candido D, Carrera JP, Li S, Zarebski AE, et al. Epidemiological and clinical characteristics of the COVID-19 epidemic in Brazil. Nat Hum Behav 2020;4(8):856-65. http://dx.doi.org/10.1038/s41562-020-0928-4.

16. Kim D, Quinn J, Pinsky B, Shah NH, Brown I. Rates of co-infection between SARS-CoV-2 and other respiratory pathogens. JAMA 2020;323(20):2085 - 6. http://dx.doi.org/10.1001/jama.2020.6266.

17. Richardson S, Hirsch JS, Narasimhan M, Crawford JM, McGinn T, Davidson KW, et al. Presenting characteristics, comorbidities, and outcomes among 5700 patients hospitalized with COVID-19 in the New York City area. JAMA 2020;323(20):2052 - 9. http://dx.doi.org/ 10.1001/jama.2020.6775.

18. Garcia-Vidal C, Sanjuan G, Moreno-García E, Puerta-Alcalde P, Garcia-Pouton N, Chumbita M, et al. Incidence of co-infections and superinfections in hospitalized patients with COVID-19: a retrospective cohort study. Clin Microbiol Infect 2020. http://dx.doi.org/10.1016/ j.cmi.2020.07.041

19. Wang M, Wu Q, Xu WZ, Qiao B, Wang JW, Zheng HY, et al. Clinical diagnosis of 8274 samples with 2019-novel coronavirus in Wuhan. medRxiv. 2020. https://www.medrxiv.org/content/101101/ 2020.02.1220022327v2. [2020-10-16].

20. Zhu XJ, Ge YY, Wu T, Zhao KC, Chen Y, Wu B, et al. Co-infection with respiratory pathogens among COVID-2019 cases. Virus Res 2020;285:198005. http://dx.doi.org/10.1016/j.virusres.2020.198005.

21. Ma SM, Lai XQ, Chen Z, Tu SH, Qin K. Clinical characteristics of critically ill patients co-infected with SARS-CoV-2 and the influenza virus in Wuhan, China. Int J Infect Dis 2020;96:683 - 7 . http://dx.doi.org/10.1016/j.ijid.2020.05.068.

22. Stowe J, Tessier E, Zhao HX, Guy R, Muller-Pebody B, Zambon M, et al. Interactions between SARS-CoV-2 and Influenza and the impact of coinfection on disease severity: a test negative design. medRxiv. 2020 https://www.medrxiv.org/content/10.1101/2020.09.18.20189647v2. [2020-10-16]

23. Hui KPY, Cheung MC, Perera RAPM, Ng KC, Bui CHT, Ho JCW, et al. Tropism, replication competence, and innate immune responses of the coronavirus SARS-CoV-2 in human respiratory tract and conjunctiva: an analysis in ex-vivo and in-vitro cultures. Lancet Respir Med 2020;8(7):687 - 95. http://dx.doi.org/10.1016/S2213-2600(20) 30193-4.

24. Suwanwongse K, Shabarek N. Can coinfection with influenza worsen COVID-19 outcomes? J Investig Med High Impact Case Rep 2020. http://dx.doi.org/10.1177/2324709620953282.

25. Hashemi SA, Safamanesh S, Ghasemzadeh - moghaddam H, Ghafouri M, Azimian A. High prevalence of SARS-CoV-2 and influenza a virus (H1N1) coinfection in dead patients in Northeastern Iran. J Med Virol 2020. http://dx.doi.org/10.1002/jmv.26364.

26. Wu P, Lu WR, He L, Meng YF, Wu P, Ding WC, et al. COVID-19 patients with recent influenza $\mathrm{A} / \mathrm{B}$ infection: a retrospective study. J Infect 2020. http://dx.doi.org/10.1016/j.jinf.2020.05.050.

27. Ceccarelli G, d'Ettorre G, Innocenti GP, Mastroianni CM, Ciccozzi M, d'Ettorre G. Is previous influenza-like illness a potential Trojan horse for COVID-19? Crit Care 2020;24(1):503. http://dx.doi.org/10. 1186/s13054-020-03226-5.

28. WHO. WHO COVID-19 weekly operational update. WHO. 2020. https:/www.who.int/docs/default-source/coronaviruse/situation-reports/ 20201005-weekly-epi-update-8.pdf. [2020-10-12].

29. Fink G, Orlova-Fink N, Schindler T, Grisi S, Ferrer AP, Daubenberger $\mathrm{C}$, et al. Inactivated trivalent influenza vaccine is associated with lower mortality among COVID-19 patients in Brazil. medRxiv. 2020. https:// www.medrxiv.org/content/10.1101/2020.06.29.20142505v1. [202010-16].

30. Jehi L, Ji X, Milinovich A, Erzurum S, Rubin BP, Gordon S, et al. Individualizing risk Prediction for positive coronavirus disease 2019 testing: results from 11, 672 patients. Chest 2020;158(4):1364- 75 . http://dx.doi.org/10.1016/j.chest.2020.05.580.

31. Zanettini C, Omar M, Dinalankara W, Imada EL, Colantuoni E Parmigiani G, et al. Influenza Vaccination and COVID-19 Mortality in the USA. medRxiv. 2020. https://www.medrxiv.org/content/10.1101/ 2020.06.24.20129817v1. [2020-10-16].

32. Amato M, Werba JP, Frigerio B, Coggi D, Sansaro D, Ravani A, et al. Relationship between influenza vaccination coverage rate and COVID19 outbreak: an Italian ecological study. Vaccines (Basel) 2020;8(3): 535. http://dx.doi.org/10.3390/vaccines 8030535 .

33. Eldanasory OA, Rabaan AA, Al-Tawfiq JA. Can influenza vaccine modify COVID-19 clinical course? Travel Med Infect Dis 2020;37: 101872. http://dx.doi.org/10.1016/j.tmaid.2020.101872. 